\title{
The impact of social media in Sri Lanka: issues and challenges in mental health
}

\author{
Rajiv Weerasendera
}

\section{Summary}

Several suicides were reported in Sri Lanka recently where there were sufficient reasons to believe that the deaths were the direct result of the victims' engagement with social media. Suicides-and other mental health problemsprecipitated or propagated by social media is a global issue and are by no means confined to Sri Lanka. Restricting access to social media is not an option. Such measures are usually counterproductive and authorities promptly announced that such a measure is not being contemplated. Since policing social media has not proven successful, an appropriate response would be to design technology that helps to identify suspicious online behaviours, promoting parental supervision of social media activity when indicated, encouraging users to report cyberbullying or sexually predatory behaviour and educating users, especially those in vulnerable age groups about inappropriate behaviour on social media. It is a process that needs to be set in motion urgently and efficiently instead of being relegated to the bottom of a priority list when news of the social media inspired suicides are swept away from the headlines.

SL J Psychiatry 2014; 5 (1): 1-2

Several suicides were reported in Sri Lanka recently where there were sufficient reasons to believe that the deaths were the direct result of the victims' engagement with social media (1). There has been much public discussion thereafter regarding the phenomenon. Suicides-and other mental health problems-precipitated or propagated by social media is a global issue and are by no means confined to Sri Lanka. However, its emergence in the Sri Lankan context provides a particular conundrum.

A by-product of the internet, social media is a term loosely used to denote a variety of web based tools that purportedly encourage communication. Social media is now ubiquitous and its growth in Sri Lanka has been exponential: the country, with a population of 21 million, has over 2.3 million users of social media, over $60 \%$ of them male. It is estimated that on average they spend about 34 minutes a day on social media (2). These statistics-and the predictable growth of the younger segment of the population-point to even more proliferation of social media in the foreseeable future; hence the importance of coming to terms with this technological invention and developing the capacity to minimise its adverse consequences.

Restricting access to social media is not an option. Indeed, when the recent suicides were reported in quick succession, there was a demand from some quarters to ban the media responsible within the country. Such measures are usually counterproductive and authorities promptly announced that such a measure is not being contemplated (3).

Despite its obvious advantages in disseminating information and enhancing communication, that social media can have a negative impact on mental health had been observed, as far back as nearly fifteen years ago when such communications were in their infancy: a survey by Kraut et al concluded that greater use of the internet was associated with declines in participants' communication with family members in the household, declines in the size of their social circle and increases in depression (4).
Since then, more evidence has emerged to bolster the argument that social media has an adverse impact on its users' mental health. A recent study of users of a popular social media provider revealed that, while social media is an invaluable resource for fulfilling the basic human need for social connection, it undermines the users' sense of well-being rather than enhancing it (5).

Another factor that has emerged is that individuals lacking in social skills may turn to social media as a means of compensating for their deficits. There is evidence to suggest that individuals who were lonely or did not have good social skills could develop strong compulsive internet use behaviours resulting in negative outcomes at work, school, or in their relationships (6). There is a considerable body of research which investigates the impact of social media on the younger age groups in the population who are arguably its most prolific users. The findings are of concern. In results that have been replicated elsewhere, Van den Eijnden et al demonstrated that increased use of social media in adolescents was associated with depression (7). There is also convincing data that social media increases the risk of exposure of adolescents to pornography, cyber-bullying and unwanted sexual solicitation (8). The latter may come from sexual offenders, as there is strong evidence that social media is a preferred source of contacts for this group (9).

Sri Lanka is handicapped by the paucity of research relating to the mental health impact of social media in the country. While most of the research findings regarding social media may still be relevant in a local setting, it would also not be prudent to simply extrapolate findings of studies in other countries-most of which are set in a different social and cultural context. Indeed, the lack of relevant research is not peculiar to Sri Lanka alone; there is only sparse data available on the issue in South Asia. However, suicides attributed to conflicts arising from the use of social media have been reported in other countries in the region (10). 
Sri Lanka boasts of the second highest literacy rate in South Asia, only less than that of the Maldives which however has a comparatively smaller population (11). It also has a high percentage of internet penetration of $15 \%$ of the population (12). These demographics suggest that social media is a potent instrument among the younger age groups of the Lankan population.

Despite a more liberal outlook emerging in recent years, the social milieu in the country remains essentially conservative. Hence any fallout as a result of interactions with social media, especially if they were to be of an intimate nature, is perceived as public humiliation. This is the context that drives users towards self-harm.

Since policing social media has not proven successful, an appropriate response would be to design technology that helps to identify suspicious online behaviours, promoting parental supervision of social media activity when indicated, encouraging users to report cyberbullying or sexually predatory behaviour and educating users, especially those in vulnerable age groups about inappropriate behaviour on social media. These strategies will provide social media users with a sense of strength and security instead of having to seeking refuge in self-harm.

These changes involve attitudinal shifts. They will not occur overnight. They also require collaboration between law enforcement authorities, internet service providers, the media, educationists and mental health professionals. The latter alone, being a scarce resource already, cannot shoulder the burden of tackling the unfortunate psychological consequences of the internet revolution. The state is perhaps in the best position to co-ordinate this effort. It is a process that needs to be set in motion urgently and efficiently instead of being relegated to the bottom of a priority list when news of the social media inspired suicides are swept away from the headlines.

\section{Declaration of interest \\ None}

\section{Rajiv Weerasundera}

Department of Psychiatry, Faculty of Medical Sciences,

University of Sri Jayawardenepura, Sri Lanka

E mail: rajivweerasundera@yahoo.com

\section{References}

1. Colombo Page. Sri Lanka mulls strategy to address adverse impact of social media on youth. Available at: http://www.colombopage.com/archive_14A/ Feb22 1393087318CH.php (accessed 24.06.2014)

2. Readme. Sri Lanka's IT Climate: we're down a few points. Available at: http://readme.lk/sri-lanka-slides/ (accessed 24.06.2014)

3. The Republic Square. President says Facebook is a "disease" in Sri Lanka. Available at: http://www. therepublicsquare.com/politics/2013/10/10/presidentsays-facebook-is-a-disease-in-sri-lanka/ (accessed 24.06.2014)

4. Kraut R, Patterson M, Lundmark V, Kiesler S, Mukopadhyay T, Scherlis W. Internet paradox. A social technology that reduces social involvement and psychological well-being? Am Psychol. 1998; 53(9):1017-31.

5. Kross E, Verduyn P, Demiralp E, Park J, Lee DS, et al. (2013) Facebook Use Predicts Declines in Subjective Well-Being in Young Adults. PLoS ONE 8(8): e69841. doi:10.1371/journal.pone.0069841

6. Junghyun Kim, Robert LaRose, and Wei Peng. CyberPsychology \& Behavior. 2009: 12(4): 451-455. doi:10.1089/cpb.2008.0327.

7. Van den Eijnden RJ, Meerkerk GJ, Vermulst AA, Spijkerman R, Engels RC. Online communication, compulsive Internet use, and psychosocial well-being among adolescents: a longitudinal study. Dev Psychol. 2008; 44(3):655-65. doi: 10.1037/0012-1649.44.3.655.

8. Valkenburg PM, Peter J. Online communication among adolescents: an integrated model of its attraction, opportunities, and risks. J Adolesc Health. 2011; 48(2):121-7. doi: 10.1016/j.jadohealth.2010.08.020.

9. Dowdell EB, Burgess AW, Flores JR. Original research: online social networking patterns among adolescents, young adults, and sexual offenders. Am J Nurs. 2011;111 (7):28-36; quiz 37-8. doi: 10.1097/01. NAJ.0000399310.83160.73.

10. Andrew Berry. Facebook Teen Suicide: Teenage Girl In India Kills Herself After Parents Ban Her From Using Facebook. Available at: http://www.ibtimes. com/facebook-teen-suicide-teenage-girl-india-killsherself-after-parents-ban-her-using-facebook-1442486 (accessed 24.06.2014)

11. UNICEF. 2011 South Asia data Pocketbook. Available at: http://www.unicef.org/rosa/Final_Booklet_29 March(2).pdf (accessed 24.06.2014)

12. Internet world stats. Internet usage in Asia. Available at: $\mathrm{http}: / / \mathrm{www}$. internetworldstats.com/stats3.htm (accessed 24.06.2014) 